\title{
10 K一モアレ法による水面形状の可視化
}

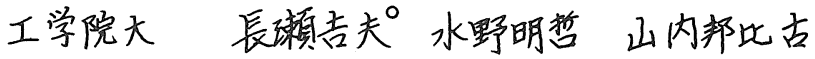

Visualization of Liquid Surface form by K-Moire Method

Yoshio NAGASE, Akisato MIZUNo, Kunihiko YAMAUCHI ${ }^{*}$

\begin{abstract}
A new visualization technique is introduced to know the shape of liquid surface. This method, which we named 'K-Moire method', is excellent in the point that it is possible to see very small disturbances of the surface with high resolution compared with ordinary grid lighting Moire method.

In this paper detailed technique for the visualization is explained. The grid used here is made of nylon string $0.23 \mathrm{~mm}$ in diameter which is arranged with $0.5 \mathrm{~mm}$ pitch using screw notch.

The lines in the pattern observed is not defined as contour lines, but the pattern could be reproduced by digital plotter after numerical analysis.

Experimental examples are presented for simple surface shapes, which are paraboloid of revolution and combined vortex. For both cases the computer plots are shown together, and they agreed with experimental results pretty well.
\end{abstract}

\section{1.まえがき}

流孔によって起こる自由表面の变化の形状を可視化する方法としてモアレ法が ある。中でも格子照射法は、夜面に近接して置かれた格子を点光源により照射市 ることにより等高線縞を生じる。こ北と似た手法で面光源を用いたのが本報で述 べる手法であり、これをKーモアレ法と名付外る。この手法て見られる縞屿等高線 とは異なり、液面の形状に㐫じて敏感に反㐫を示す特有のものでする。

本研究はこのK+モアレ法が弱い滑等の可視化に有効であることに着目レ、手础 の紹分に重点を置き。简单古水面形状(強制渦, 組み合わせ渦)についての实験 結果と理論解析との对忘を述べるものである。

2. 实験装置おすび方法

Fig. 1 は強制滑(回転放物面) を可視化する場合の装㯰の概略図无万。座標 は格子の中心に原点を定め，格子面を 方向に平行であり、紙面に慜直に向か门方向である。

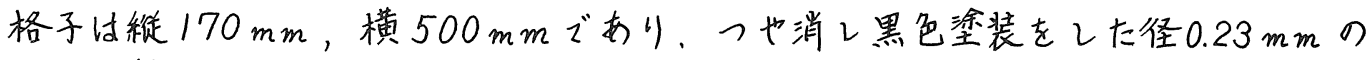
ナイロン製釣系をネジのピッチを利用して $0.5 \mathrm{~mm}$ 間隔に張ったものである。設 定は微動装置により格子面と静止水面とが平行になるように才万。

* Department of Mechanical Engineering, Kogakuin University, Nishi-Shinjuku, Shinjuku-ku, Tokyo 
光源は面光源であるために可視化寸る簯 国をカバーするものが必要である。本实验 讪縱 $200 \mathrm{~mm}$ ，横 $650 \mathrm{~mm}$ の面光源意得 るために500W棒状八ロゲンランプ3個を 道線状に配し，反射板前面に取り付计た卜 レーシングペーパー全体を均等に照万すす うに午っている。

容器は直径 $160 \mathrm{~mm}$, 高さ $160 \mathrm{~mm}$ の円 筒形の方のを使用し、回䎐数を調整で等る レコードプレーヤ一を用いて实験レた。

撮影には一眼しフカカラを使用レた。长 の際、鮮明な稿を得るには絞りを絞ってピ ントを格子面に合わせることが大切である

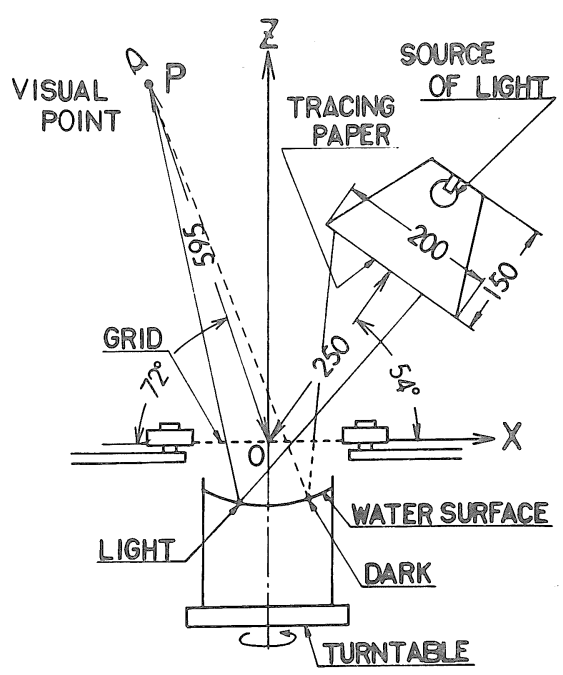

。并のため、十分をシャッ夕一速度に才る には增感現像が必要である。

なお、水面には従来のモ了レ法のように マル三粉等を浮かせる必 要はないが、より鮮明尓 縞を胃るに恔哭内面を 黑色つ也消し叙装に才る。

組斗合わ世淂について は、速度の異をる平行流 の境界方生じる滑( ${ }^{(2)}$ F i g . 2）を可視化した。Fig.

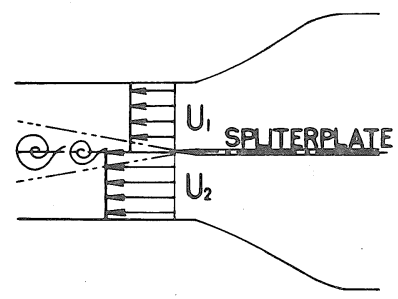

Fig. 2 Schematic Illustration of Shear Flow between Two Parallel Streams

了は上述と同じ装置を回

Fig.1 Apparatus for the Visualization by K-Moire Method 流水槽测定部にセットレたところである。 3. 実験結果

\section{1 静止水面}

Fig. 4 は水面が静止していると造に視点P $(-170$ $\mathrm{mm} ， 0 \mathrm{~mm} ， 570 \mathrm{~mm}$ ) の位置加万見上縞模粎i゙ ある。水平面に生じる縞は張って方系の方向に平

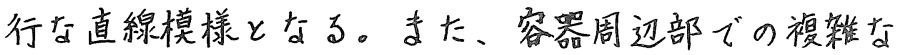
縞付表面張力により面形状に急等变化老生じたとこ 万で执る。二の写真は格子と水面との間隔が $30 \mathrm{~mm}$

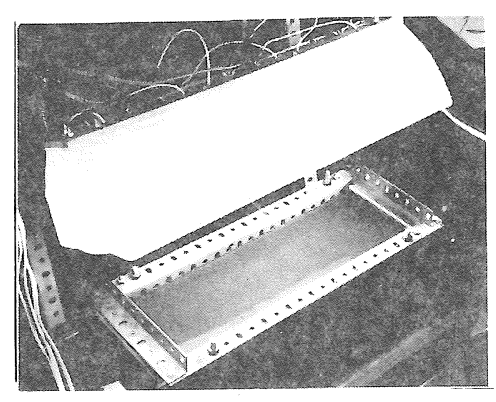

Fig.3 Photograph of assembly

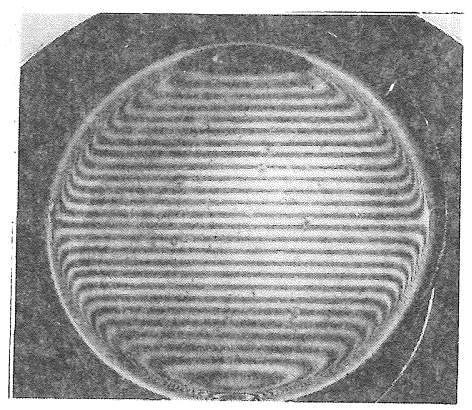

Fig. 4 Water Surface at Rest であるが、間隔が広がるほど縞数が增元細かくなる。 3.2 強制渦(回転放物面) 
Fig. $5(a),(b),(c),(d)$ は 静止水面と同じ視点位置力 万見た回転放物面によって 生じる縞模样である。図中 のメ印山回転放物面の中心 を示レている。回䎐数 (rpm ) it (a) $30,(b) 35,(c) 39,(d)$ 45 ぞり、格子と自由表面 最深部っまり回転放物面の 中心゙との間隔が $30 \mathrm{~mm}$ に尓 っている。ここで、面形状 は次式によって与え弓れる。

$$
\begin{gathered}
z=\frac{r^{2} \omega^{2}}{2 g}+H \\
\left(r^{2}=x^{2}+y^{2}\right)
\end{gathered}
$$
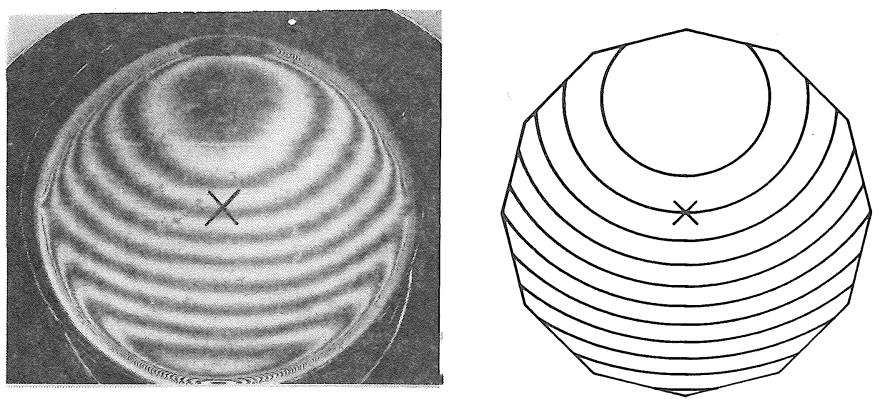

(a) $30 \mathrm{rpm}$
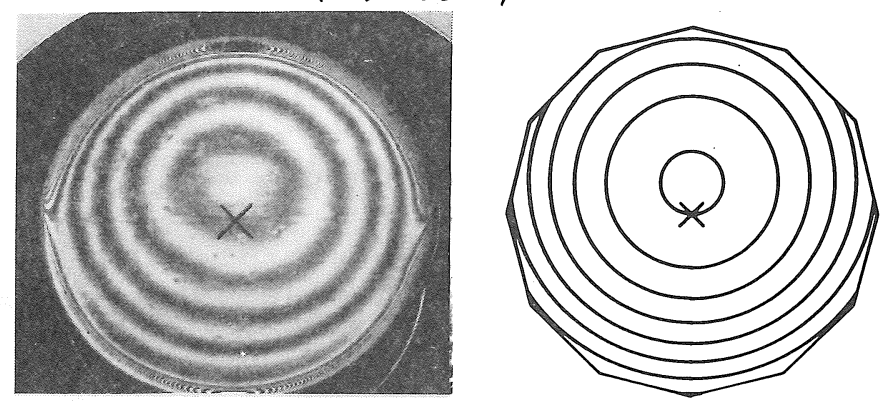

「は回転中心からの半径、 山は角速度， $g$ は重力加速 度、十は自由表面最深部门 区座標である。いま。 $50 \mathrm{~mm}$ を例にとると、中心゙ との水位差は(a) $1.26 \mathrm{~mm}$ , (b) $1.7 / \mathrm{mm}$, (c) $2.13 \mathrm{~mm}$

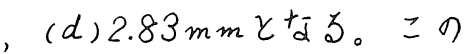
二とから，水面形状のわ术 か亦变化に赫し亿著しく縞 模様が变化していることが わ力る。

\section{3 組开合わ世滑}

Fig. 2 に示されたすうに 速度的異なる平行流的境界

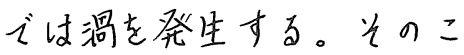
とを明確に知るために水面 に染料を流すことにより可 視化レた写真がFig.6であ る。流速は $U_{1}=6.0 \mathrm{~cm} / \mathrm{sec}$ (上

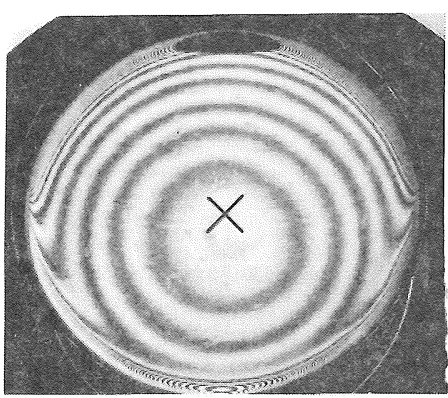

(C) $39 \mathrm{rpm}$

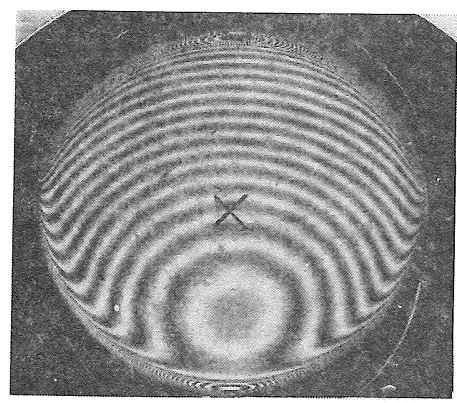

(d) $45 \mathrm{rpm}$

Fig.5 Paraboloid of Revolution
Fig.9 Numerical Plot of

Paraboloid
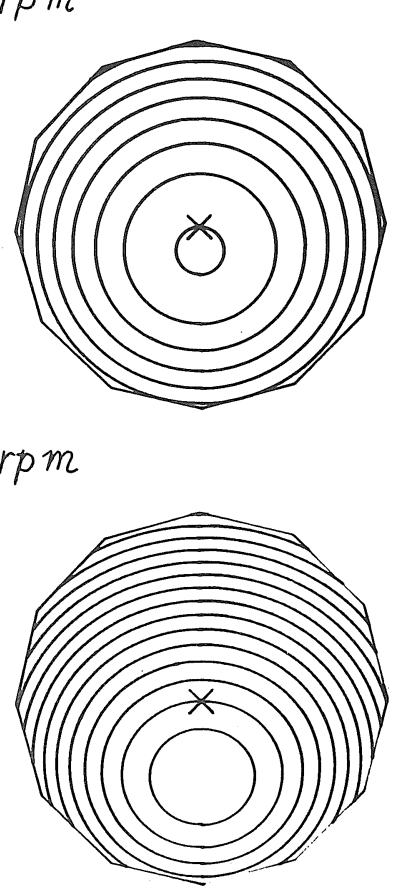
侧)， $U_{2}=20.0 \mathrm{~cm} / \mathrm{sec}$ (下側) である。 同じ流水を視点 $(-520 \mathrm{~mm}, 0 \mathrm{~mm}$ ， $1280 \mathrm{~mm})$ の位置か5K一モアレ法に より可視化したのがFig.7である。 Fig.8讨々の中の1つの滑を拡大レ たものた、回転放物面の場合と讨ま ったく異なる縞模样をしている。 4. 理論解析との比較

水面の形状が主 $=f(x, y)$ の形 $i$ 与えられる場合に、このKーモアレ法 により生じる縞模様は、格子上のお る一点を胃たと这に、点が明る いか暗いわによって予剢できる。

このことは、光の反射の法 則と格子ピ・チとの関係から 求めることができる。

前ページのFig. 9 (a), (b)， (c)，(d)过転放物面につい て得た結果で、之水尤水が Fig.5に浔忘才る。面形状は 式(1)によって与元に。

組み合わ消についてはう ンキン消の式が一般的文る が、水面の变曲点において勾

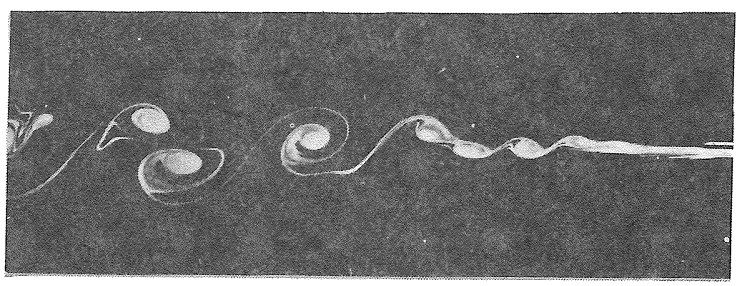

Fig. 6 Shear Flow Vortex by Tracer Method

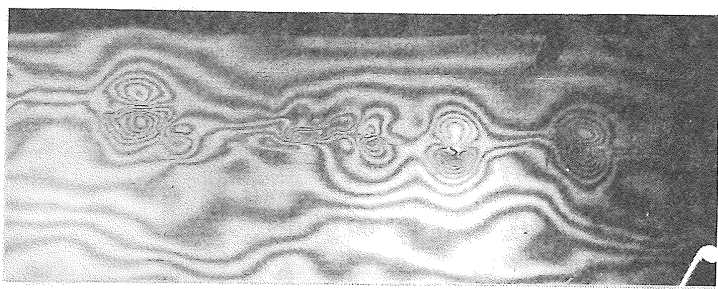

Fig.7 Shear Flow Vortex by K-Moire Method

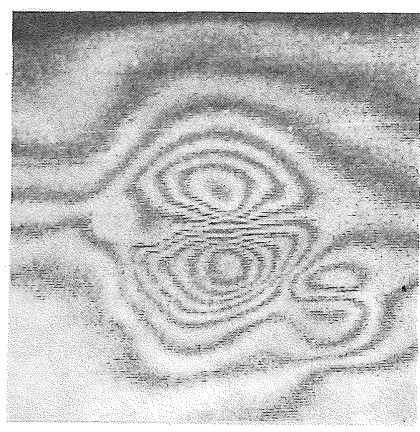

Fig. 8 A Vortex in Shear Flow

(Fig. 7)

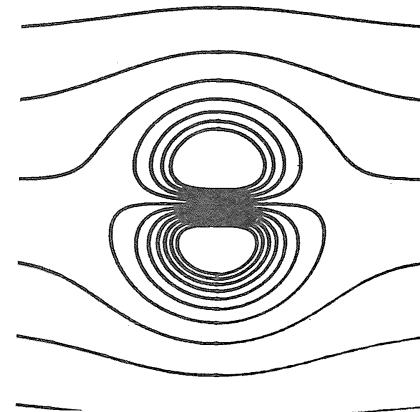

Fig.10 Numerical Plot of Combined Vortex

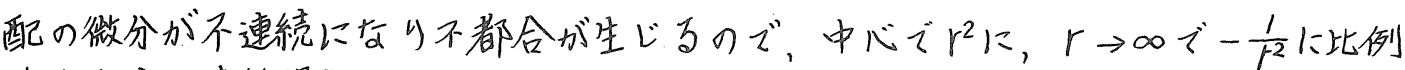
するすう尔連続関数

$$
z=2 \cdot \frac{h}{\pi}\left(\tan ^{-1} \frac{r^{2}}{3 a^{4}}-\frac{\pi}{2}\right)+H \quad\left(r^{2}=x^{2}+y^{2}\right)
$$

を使用した。Hはr

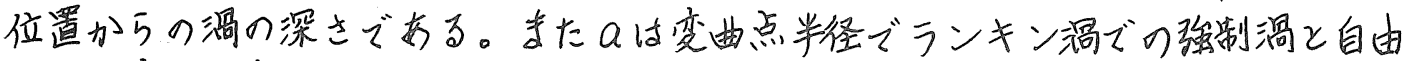

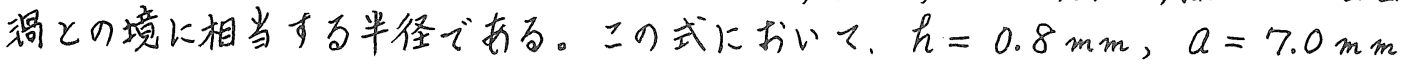
のときに得た結果がFig.10であり、Fig.8の可視化にするものとかなり一致して

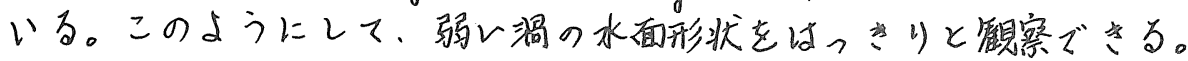

文献 (1) 浅沼偏: 可視化ハンドブック, 朝含音店 (1977), p385 361

(2) A.Roshko: J.Fluid. Mech. (1974), vol.64, part 4, p $775 \sim 816$ 